\title{
A PRODUÇÃO COLABORATIVA NO TELEJORNALISMO: UM ESTUDO SOBRE A APROPRIAÇÃO DE CONTEÚDOS PRODUZIDOS PELO TELESPECTADOR-USUÁRIO PELO SPTV
}

\author{
The collaborative production in telejournalism: a study on the appropriation of \\ contents produced by the user-viewer by SPTV
}

La producción colaborativa en el telediario: un estudio sobre la apropiación de contenidos producidos por el espectador-usuario por el SPTV

Vicente William da Silva Darde

Coordenador de Jornalismo - FIAM-FAAM Centro Universitário vicente.darde@fiamfaam.br

Fernando Albino Leme

Coordenador de Rádio e TV - FIAM-FAAM Centro Universitário fernando.leme@fiamfaam.br

\section{Resumo}

Ferramentas e tecnologias digitais disponíveis possibilitam, na atualidade, que o cidadão atue como colaborador na produção de notícias. Ao capturar a realidade pelas câmeras dos smartphones ou tablets, o espectador-usuário busca compartilhar essas informações "brutas" com o maior número de pessoas possível, por isso o envio desse material para as emissoras de TV se torna um atrativo. Porém, a apropriação desse material informativo pelos jornalistas propicia uma participação efetiva do público na produção da notícia? Para além disso, essa produção colaborativa nas coberturas dos telejornais resulta em relatos mais plurais e contextualizados dos acontecimentos? Em busca dessas respostas, analisamos a utilização do material colaborativo pelo SPTV $1^{\mathrm{a}}$ edição, um dos principais telejornais exibidos pela TV Globo na cidade de São Paulo.

Palavras-chave: Telejornalismo. Conteúdo colaborativo. SPTV.

\begin{abstract}
Available digital tools and technologies make it possible for the citizen to act as a collaborator in the production of news. By capturing reality from smartphone or tablet cameras, the viewer-user seeks to share this "raw" information with as many people as possible, so sending this material to TV stations becomes an asset. However, does the appropriation of this information material by journalists allow an effective participation of the public in the production of news? Moreover, does this collaborative production of news coverage give rise to more pluralistic and contextualized relations of events? In search of these answers, we analyze the use of the collaborative material by SPTV $1^{\text {a }}$ edition, one of the main telenewspapers exhibited by TV Globo in the city of São Paulo.
\end{abstract}


Key words: Telejournalism. Collaborative content. SPTV.

\section{Resumen}

Las herramientas y tecnologías digitales disponibles posibilitan, en la actualidad, que el ciudadano actúe como colaborador en la producción de noticias. Al capturar la realidad por las cámaras de los smartphones o tablets, el espectador-usuario busca compartir esa información "bruta" con el mayor número de personas posible, por lo que el envío de ese material a las emisoras de televisión se vuelve un atractivo. Sin embargo, la apropiación de ese material informativo por los periodistas propicia una participación efectiva del público en la producción de la noticia? Además, esa producción colaborativa en las coberturas de los telediarios resulta en relatos más plurales y contextualizados de los acontecimientos? En busca de esas respuestas, analizamos la utilización del material colaborativo por el SPTV $1^{\text {a }}$ edición, uno de los principales telediarios exhibidos por TV Globo en la ciudad de São Paulo.

Palabras clave: noticiario de TV. Contenido colaborativo. SPTV.

\section{INTRODUÇÃO}

O uso das tecnologias digitais, como smartphones e tablets, tem crescido entre a população brasileira, principalmente nos grandes centros urbanos, para o registro de fatos do cotidiano. Em um estudo sobre o telespectador como produtor de conteúdo, Musse e Thomé (2015) afirmam que a participação do público no telejornalismo atravessa os noticiários regionais, tornando esse público um "aliado" que abastece o noticiário de imagens. Em grande parte dos vídeos enviados pelos telespectadores às emissoras, os conteúdos estão vinculados à denúncia e reclamação, como identificaram Musse e Thomé (2015) na análise da participação do público no RJTV, telejornal da TV Globo exibido no Rio de Janeiro. Ao enviarem esse material, apontam as autoras, os cidadãos “[...] entregam ao telejornal a função de defensor e de mediador na sua relação com o poder público, legitimando o poder da imprensa" (2015, p.05).

Compreendemos que os telejornais, principal gênero jornalístico das emissoras de televisão, podem funcionar como instrumentos de conservação ou mudança social a partir dos discursos produzidos sobre os fatos diariamente e "consumidos" por milhões de telespectadores no Brasil. A TV possui um lugar importante nas identidades culturais, pois unifica a sociedade ao oferecer referências nacionais da realidade cotidiana, revela conflitos e viabiliza mudanças através de sua mediação. A partir dessas premissas acerca do telejornalismo brasileiro, acreditamos que representações sobre a realidade são (re)construídas a todo momento em que um noticiário televisivo entra no ar. A crença de que o jornalismo 
reflete a realidade faz com que o público reconheça e construa o seu mundo através das telas dos aparelhos televisivos, e atualmente pelas telas de smartphones e tablets. Por esses motivos, compreendemos como indispensável a compreensão das estratégias discursivas utilizadas pelos telejornais para mostrar essa realidade.

Nesse contexto, buscamos observar se a produção colaborativa ${ }^{1}$ em formato audiovisual nas coberturas dos telejornais, especialmente do SPTV, principal produto jornalístico da TV Globo na cidade de São Paulo, possibilita a construção, por parte dos jornalistas, de relatos mais plurais e contextualizados do cotidiano, contribuindo para a promoção da diversidade no telejornalismo praticado pela TV Globo SP.

Pretendemos também compreender se esses conteúdos colaborativos utilizados pelo telejornalismo permitem novos modos de falar e representar as relações entre a população paulistana e sua metrópole. Este artigo faz parte dos estudos do Projeto de Pesquisa "Telejornalismo, narrativas e representações: um estudo sobre a cidade de São Paulo no século XXI" do Mestrado Profissional em Jornalismo do FIAM-FAAM Centro Universitário.

Sua pertinência é justificada pela análise da reconfiguração das práticas e linguagens dos noticiários televisivos e seus impactos sobre os processos de noticiabilidade e valores referenciais do jornalismo com relação à cidade de São Paulo. Para este artigo, decidimos analisar de que forma o SPTV $1^{\text {a }}$ edição se apropriou do conteúdo enviado pelos telespectadores em edições aleatórias no primeiro semestre de 2016, verificando se esses conteúdos e formatos agregam novos ângulos e pontos de vista na transformação dos fatos em notícia e se contribuem para estabelecer novas linguagens no telejornalismo.

\section{TELEJORNALISMO COMO MEDIAÇÃO DA REALIDADE}

A televisão e os telejornais se consolidaram no Brasil como um território simbólico. Juntos, assumem um papel de conservação das relações de poder e, consequentemente, um controle social no agendamento cultural e político da sociedade. Conforme Squirra (1995, p.12), “como a televisão é tão imediata e atinge uma audiência tão vasta, com uma eficiência tecnológica surpreendente, ela parece capaz de tudo, inclusive de mostrar a verdade em momentos em que ela necessariamente não pode ser conhecida”.

\footnotetext{
${ }^{1}$ Optamos por adotar o termo de jornalismo colaborativo para a participação dos telespectadores no envio de conteúdos em vídeo para as emissoras de TV. No entanto, sabemos que esse modelo também é denominado de participativo, cidadão e open source, dentre outras definições.
} 
Os telejornais ainda são os produtos de informação de maior impacto na atualidade no Brasil, e ocupam lugares estratégicos nas programações televisivas e recorrentemente funcionam como única expressão coletiva de construção social da realidade, configurando-se um espaço importante de elaboração de sentidos. Squirra (1995, p.14) afirma o telejornal é o tipo de programa que traz mais credibilidade para a emissora pela capacidade que tem de falar para um público diverso: "credibilidade junto aos anunciantes [...] e prestígio junto ao poder político e econômico da nação".

Os telejornais ocupam lugares estratégicos na programação das redes e também nos discursos midiáticos contemporâneos. Uma das principais características da linguagem dos noticiários é garantir a verdade ao conteúdo do discurso, também a própria credibilidade do enunciador. Os telejornais utilizam jogos de sentido que resultam numa objetividade e no mito da imparcialidade. Os discursos provocam efeitos de realidade e se confundem com o real porque os personagens são reais e os fatos são sociais. Duarte e Curvello (2009) definem que:

O discurso do telejornal constrói-se tomando como referência o mundo real, exterior à mídia; trata-se de uma meta-realidade, cujo regime de crença proposto é a veridicção. Assim, o que funda os telejornais e lhes confere legitimidade é o relato objetivo do real, do mundo exterior. Uma boa notícia, dizem, deve ficar o mais próximo possível do acontecimento, mantendo em relação a ele fidelidade, neutralidade, objetividade. É aí que entra em questão a verdade, pois a partir de um mesmo fato ou acontecimento, podem ser produzidos relatos bastante diferentes, todos verdadeiros, porque respeitam as fontes, mas todos diversos, porque operam seleções, focalizações e montagens diferentes: a televisão não reflete o real, ela o conforma. (DUARTE e CURVELLO, 2009, p. 69)

Estes discursos se constroem, se estruturam, produzem significações e até mesmo relativizam o seu poder, afinal, o telejornal tem linguagem e discurso complexos, estratégias singulares, que devem ser reveladas para que possamos compreender o telejornal como um gênero. Vale ressaltar que nenhum noticiário é igual ao outro, eles se diferenciam pela maior ou menor competência de tratar as informações sobre os principais acontecimentos, gerar recursos financeiros e técnicos, de atingir e conquistar audiências.

O telejornal exerce uma função política e, ao mesmo tempo, pretende ser uma abertura para o mundo. Os modos de construção e transmissão das notícias acabam por intervir em outros campos sociais, especialmente na política. A função do telejornal é narrar os principais 
fatos sociais de diferentes países em todo o mundo, mas simultaneamente reordena a experiência social do cidadão nas cidades e em diferentes comunidades. Motta (2004) explica que as narrativas criam significações sociais, são produtos culturais inseridos em certos contextos históricos, como as crenças, os valores, as ideologias e a política na sociedade.

Na narrativa da mídia televisiva, Mota (2006) destaca que a análise precisa levar em conta que o plano de expressão é constituído de duas formas de representação: a imaginação e a verbal. Para facilitar a compreensão por parte do telespectador, a autora observa que o código visual na TV é de natureza convencional.

A estratégia utilizada pela mídia televisiva para a construção de sentidos sobre a realidade é a referenciação. Como afirma Mota (2006, p.133), "o texto constrói a referência em imagem, dando-lhe atributos, da mesma forma que se alimenta da imagem para se autoconstruir”. Os significados construídos pelo texto jornalístico geram efeitos de realidade.

\section{PARTICIPAÇÃO DO PÚBLICO NA PRODUÇÃO DE NOTÍCIAS}

A produção de imagens, seja estática ou em movimento, pela população, e o envio desse material para ser utilizado jornalisticamente pelos veículos de comunicação, tem alterado a rotina de produção das notícias. A popularização de smartphones e tablets, a partir do barateamento da tecnologia, além da facilidade de gravação, edição e envio de vídeos por meio das redes sociais e dos sites das empresas de comunicação, possibilitaram e estimularam a produção de conteúdo colaborativo. Musse e Thomé (2015) problematizam, inclusive, o efeito de fim da mediação, pois o material produzido pelo telespectador é exibido diretamente no telejornal, mesmo com ruídos, movimentos disformes e outras características que fogem da estética tradicional da produção da reportagem televisiva.

Para tratarmos desse efeito de participação do público na produção de notícias, recorremos aos estudos realizados por Kieling (2012), que defende a presença de pelo menos quatro níveis de enunciadores (locutores ou narradores), nesses textos de construção colaborativa. Os estudos defendem que a participação do público se caracteriza como quarta instância de enunciação. Anteriormente, existem os níveis de enunciadores que se caracterizam no enunciador ausente, que podemos compreender como as orientações da empresa (linha editorial); narrador implícito (produtor, cinegrafista, editor) e o narrador ou autor concreto, presente no papel desempenhado pelo apresentador, repórter ou entrevistado (KIELING, 2012). 
O autor, ao adotar essa perspectiva, baseado nas tipificações de Jost (2004) e Jimenez (1996), afirma acreditar que a inscrição do telespectador na colaboração do relato do telejornal ainda é uma promessa. "Ele envia seus textos, mas todos os conteúdos invariavelmente passam pelos filtros dos sistemas de produção e dos outros enunciadores" (KIELING, 2012, p.10). De acordo com o autor, o telespectador colaborativo ainda se circunscreve a uma dimensão virtual, pois o material do telespectador é mediado na edição e apresentação.

O empoderamento do telespectador parece já ser uma realidade com o uso da internet de forma complementar. Por meio do fenômeno da segunda tela, pela qual os usuários comentam e compartilham nas redes sociais o conteúdo exibido pelas emissoras de TV, a interação se intensifica e ajuda a modificar as relações entre produtores e consumidores de notícias. Finger (2014, p.219) aponta que essa “[...] é a oportunidade de estender a conversa da sala de estar para qualquer outro lugar, amplificando o poder do telespectador e também reforçando o laço social". Uma televisão com novas características como maior interação entre emissor e receptor, empoderamento do telespectador e introdução de novas linguagens multimídia e interativa com estímulo à participação foi definia por Scolari (2004) como hipertelevisão² .

A notícia pode nascer numa publicação no Twitter ou numa conversa no Facebook, chegar à redação da TV, passar pelo jornal e repercutir em qualquer outro meio, com linguagens, estéticas e narrativas diferentes e complementares (TOURINHO, 2012). A esta expansão soma-se outro elemento da hipertelevisão que é a colaboração dos usuários na construção do conteúdo, enviando textos, fotos, comentários ou sugestões de pautas. De acordo com Tourinho (2012), em meio à crise de audiência estabelecida diante da oferta de novos e cada vez mais frequente canais informativos, os veículos tradicionais, e notadamente a TV aberta, passam cada vez mais a buscar atender os apelos do público que, por sua vez, também almeja em muitos casos participar no processo de criação de novos formatos, tornando-se muitas vezes protagonistas desse modelo.

Na análise de Musse e Thomé (2015, p.02), “a participação dos telespectadores contribui na construção do cotidiano e das representações sobre uma parte da cidade que pode ficar muitas vezes à margem do olhar do poder público e da própria imprensa". Entendemos que esse é um dos pressupostos do jornalismo comprometido com o interesse público. Os processos de formação e transformação das representações sociais são dependentes da ação

\footnotetext{
2 A hipertelevisão é uma televisão instalada em uma sociedade em rede, nos termos definidos por Castells (1999). Para este, a sociedade se desloca de um sistema de mídias de massa para um sistema multimídia especializado e fragmentado, com audiências segmentadas.
} 
comunicativa, portanto são instituídas tanto na conversa direta entre pessoas quanto na comunicação midiática. Nessa lógica, compreendemos o jornalismo como uma prática midiática produtora de representações.

Representar é atribuir sentido, classificar e/ou lutar pela imposição de significados, e a representação pode ser vista como uma prática social que produz cultura, conforme Hall (2003). As representações sociais ${ }^{3}$ têm como uma de suas finalidades tornar familiar algo nãofamiliar, isto é, uma alternativa de classificação, categorização e nomeação de novos acontecimentos e ideias, com a quais não tínhamos contato anteriormente, possibilitando, assim, a compreensão e manipulação destes a partir de ideias, valores e teorias já preexistentes e amplamente aceitas pela sociedade. "Depois de uma série de ajustamentos, o que estava longe, parece ao alcance de nossa mão; o que era abstrato torna-se concreto e quase normal”, define Moscovici (2003, p.58).

Ao mesmo tempo em que são modos de exposição que naturalizam certos vieses, as representações midiáticas podem instaurar padrões normais e modelos que influenciam as percepções sobre as coisas do mundo. Verificando a construção do discurso no campo do jornalismo, Correia (2008) afirma que o relato jornalístico procede ao ato de relatar de acordo com as tipificações negociadas pela comunidade jornalística, de acordo com os conceitos e valores pré-existentes na cultura de uma determinada sociedade em um determinado contexto histórico.

As representações sociais formam um conjunto de fenômenos que criam e recriam a realidade de forma dinâmica na sociedade. As representações sociais empregadas na mídia estão submetidas ao que Charaudeau (2006) denomina de contrato de comunicação regulado por um quadro de referências construídas num jogo de regulação das práticas sociais, criadas pelos indivíduos para manter a ordem na sociedade.

De acordo com a teoria das representações sociais, os processos de ancoragem e objetivação são indispensáveis para a o sucesso da ação comunicativa. Na objetivação as ideias abstratas transformam-se em imagens concretas, através do reagrupamento de ideias e imagens focadas no mesmo assunto. A ancoragem prende-se com a assimilação das imagens criadas pela objetivação, sendo que estas novas imagens se juntam às anteriores, nascendo assim novos conceitos.

\footnotetext{
${ }^{3}$ As Representações Sociais têm em Serge Moscovici a sua primeira base teórica, em 1961, através da obra "A Psicanálise, sua imagem e seu público".
} 
A seguir buscamos compreender como um dos principais telejornais da TV Globo contribui para construir novas representações acerca da cidade de São Paulo por meio do conteúdo colaborativo enviado pelos telespectadores.

\section{O CONTEÚDO COLABORATIVO NA TELA DO SPTV $1^{\mathrm{a}}$ EDIÇÃO}

O SPTV é o telejornal da TV Globo exibido no estado de São Paulo. O telejornal estreou em janeiro de 1983, com o intuito de ampliar o espaço para o jornalismo regional na grade de programação da Rede Globo. Como seus similares em outros estados, o objetivo era conferir maior identidade ao noticiário local, até então incorporado aos telejornais Hoje, Jornal Nacional e Jornal da Globo. De acordo com a seção Memória Globo no site do telejornal, jornalismo de serviço e comentários sobre os fatos mais importantes do dia davam o tom do novo telejornal, que tinha dez minutos de duração e era dividido em três blocos de cerca de três minutos cada. Contava com reportagens ao vivo, notícias sobre esporte, cobertura meteorológica e informações sobre o trânsito no estado. Formato que pouco se modificou até a atualidade.

O SPTV possui duas edições de segunda-feira a sábado: a primeira edição começa às 12 horas e a segunda edição, às 19h10 (os horários podem variar de acordo com a mudança na programação). A primeira edição dura 45 minutos e, além de fazer a cobertura das notícias do dia, conta com entrevistas no estúdio e a participação de comentaristas. Direcionado à prestação de serviços à população, o SPTV - $1^{\text {a }}$ Edição também cobra das autoridades a resolução de problemas que afetam o dia a dia dos cidadãos, marcando na Agenda do SPTV o prazo para que as situações sejam resolvidas.

O SPTV - $1^{\text {a }}$ Edição foi um dos primeiros telejornais a consolidar o conceito de jornalismo comunitário, voltando-se mais para a população local, com informações sobre os problemas de cada bairro. De acordo com o site da TV Globo, Amauri Soares, então diretor de jornalismo da TV Globo São Paulo, conta que o projeto do jornalismo comunitário foi desenvolvido a partir de três pilares: fazer dos telejornais da Globo um canal de comunicação entre as comunidades e as autoridades públicas, criando um espaço para a discussão e busca de soluções de problemas da população; documentar as dificuldades de exercer a cidadania numa região metropolitana grande e populosa como a de São Paulo; e mostrar os hábitos, comportamentos, manias e modismos dos moradores, para que eles se vissem retratados nos telejornais. 
Outra mudança significativa nos telejornais SPTV foi a estreia, em 2008, de um novo cenário com estúdio panorâmico, construído no alto do prédio da sede da TV Globo na capital paulista, às margens do Rio Pinheiros. O espaço permitiu que os telejornais locais tivessem como fundo a própria cidade de São Paulo, que tinha como propósito aumentar a proximidade dos programas com o público. Atrás dos apresentadores, uma vista de 180 graus mostra o trânsito e o clima naquela região, além de um dos cartões postais da cidade, a ponte estaiada Octavio Frias de Oliveira.

Já em 2011, com a estreia do jornalista César Tralli na bancada, veio uma reformulação visual no SPTV - $1^{\text {a }}$ Edição. Foi montado um set de entrevistas e instalados três telões para dar mais agilidade na interação com os repórteres, especialistas, convidados e tornar o programa mais dinâmico. Como jornal local, a cobertura sobre o que acontece no dia a dia da cidade se torna prioridade. Ainda mais em uma cidade como São Paulo, a maior do país, com mais de 11 milhões de habitantes, segundo o IBGE (2011).

Os telejornais regionais, como o SPTV, vem estimulando a participação da audiência não apenas como personagens ou como pauteiros, mas como produtores de conteúdo. Nesta relação, em que é simulada uma parceria entre audiência e emissora, como definem Musse e Thomé (2015, p.08), “[...] esses consumidores-produtores, no entanto, funcionam como apuradores e coletores de um material que pode ou não ser aproveitado no telejornal, de acordo com critérios dos jornalistas". A seguir, temos alguns exemplos de como esse conteúdo gerado pelo público foi reordenado pelo telejornalismo.

A reportagem exibida no SPTV $1^{\text {a }}$ edição, do dia 28 de janeiro, fala de estragos na cidade provocados por fortes chuvas. A população é representada nesta matéria por moradores que sofrem com os temporais que alagam diversas regiões, deixando pessoas ilhadas e com prejuízos em suas casas. Eles registraram com câmeras de celulares o momento em que as ruas viraram verdadeiros rios, além de mostrar o que perderam com os estragos provocados pela chuva. Essa situação acontece com frequência em alguns bairros da capital paulista. $O$ apresentador César Tralli na cabeça da reportagem fala:

A grande são Paulo amanheceu ainda tentando botar em ordem a bagunça causada pelo forte temporal de ontem à tarde. Tem árvore caída, pistas ficaram interditadas, muitos pontos de alagamento. Uma quinta-feira extremamente difícil. Apresentador, 28/01/16. 
Tralli chama ao vivo a participação da repórter Carla Modena, que está no Jaçanã, zona norte da cidade, uma das regiões mais afetadas pela tempestade. Durante a sua fala, a repórter aponta que há um córrego na região que transborda nos dias de chuva. A repórter chama a reportagem mostrando os estragos da chuva.

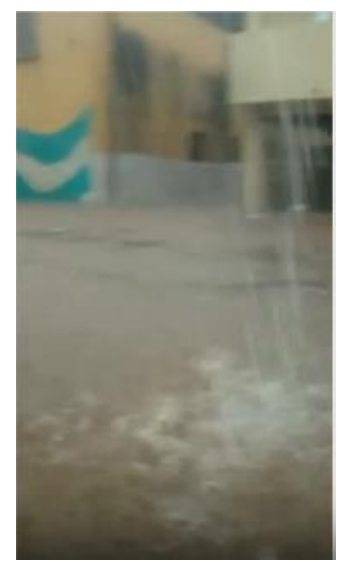

Figura 1: Imagem da enchente registrada por morador.

Durante a matéria, a matéria mostra imagens enviadas por moradores. Na narração, a repórter afirma que:

As imagens feitas pelos moradores mostram que isso aqui (a rua) virou um rio. Eles dizem que em meia hora a água subiu e muito. Repórter, 28/01/16.

No fechamento da reportagem o apresentador faz um comentário pedido providências das autoridades, cumprindo com o papel de mediador entre a sociedade e o poder público, como afirmam Musse e Thomé (2015).

Tem que ter um esforço enorme da prefeitura pra limpar esgoto, bueiros, boca de lobo, córrego, enfim, fazer de tudo pra poder evitar o pior nesses meses de verão. Agora, infelizmente vivemos numa selva de pedra que quando chove demais a água não tem pra onde escorrer e ai acontece tudo isso. Apresentador, 28/01/16.

A $1^{\text {a }}$ edição do SPTV do dia 23 de fevereiro começa tratando de um problema de saúde pública: o aumento expressivo no número de casos confirmados de dengue na capital paulista. No texto da cabeça, o apresentador César Tralli enfatiza a preocupação com a situação da doença:

Infelizmente notícia nada animadora. A dengue está explodindo em São Paulo. [...] Números não param de subir. Apresentador, 23/02/16.

Logo após, Tralli chama ao vivo a participação do repórter André Azeredo, que está em frente à Prefeitura Municipal, onde os números foram divulgados naquela manhã. Dessa forma, o telejornal reforça o caráter de estar em cima dos fatos, pautado pelo agendamento do poder público que tem o controle sobre os dados acerca da situação da saúde pública. 
O repórter fala dos números e chama uma reportagem sobre a existência de um aplicativo para smartphones pelo qual os moradores podem denunciar locais que podem ser focos da dengue na capital. A reportagem começa com imagens enviadas por um telespectador. Na narração, o repórter descreve as imagens e reforça que foram enviadas por um morador.

Uma pilha de pneus em cima da calçada. E olha dentro de um deles: água parada. Essas fotos foram enviadas pelo Peterson Andrade. Ele diz que é comum ver esse tanto de pneu na estrada de Itapecerica, pertinho do terminal João Dias. Repórter, 23/02/16.

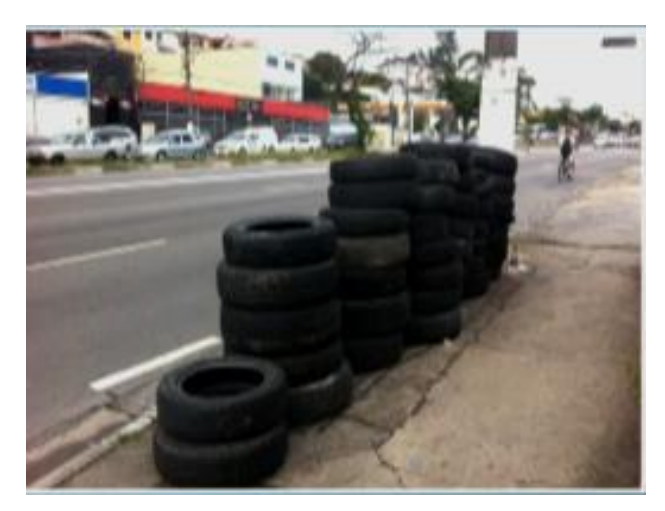

Figura 2: Morador registra pneus nas ruas.

Logo após, já com imagens feitas pelo cinegrafista da TV, o repórter explica que os moradores podem enviar essas imagens diretamente à prefeitura por meio de um aplicativo. Por meio desse discurso, compreendemos que a emissora busca aproximar o cidadão ao poder público que é diretamente responsável por aquele problema, reforçando assim o caráter de mediação do veículo de comunicação.

A violência que também faz parte do dia a dia dos paulistanos foi retratada nesta edição do dia 31 de março pelas mãos de um cinegrafista amador. Um homem entrou num Fórum e manteve uma juíza como refém durante alguns minutos. A violência contra a mulher foi representada nesta matéria.

No texto da cabeça, Tralli afirma que o Fórum do Butantã, zona oeste de São Paulo, está fechado naquele dia. No dia anterior, um homem "transtornado" entrou pela porta da frente, driblou os seguranças, manteve uma juíza da vara de violência doméstica refém. Diante das imagens adquiridas pela emissora, o apresentador reforça que o telespectador, a partir daquele momento, iria acompanhar todos os momentos finais da libertação dela. 
A repórter Sabina Simonato descreve as imagens feitas por um cinegrafista amador. Neste caso, a emissora não revela se as imagens foram compradas ou se foram cedidas gratuitamente por quem registrou os fatos. Mas esse registro mostra a relevância das imagens, mesmo feitas por alguém não preparado tecnicamente, como os cinegrafistas, para poder mostrar o momento exato da tensão pela qual passou a juíza.

Numa negociação rápida policiais civis e militares invadem a sala onde a juíza é mantida refém, disparam um extintor de incêndio e conseguem dominar o sequestrador. Alfredo José dos Santos manteve a juíza como refém por pouco mais de quinze minutos. Ele jogou um líquido escuro nela e ameaçava colocar fogo em tudo. Repórter, 31/03/16.

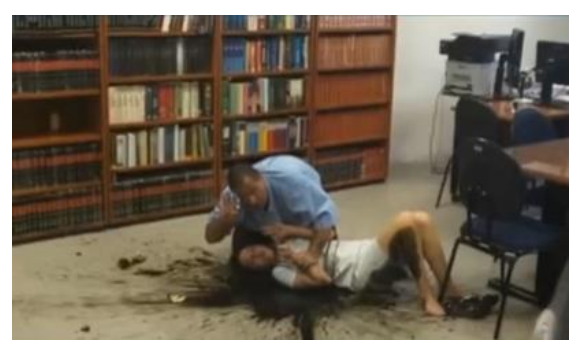

Figura 3: registro da juíza como refém.

Após a exibição da reportagem, o apresentador ressalta o grande número de mulheres agredidas em São Paulo e reforça o profissionalismo da juíza.

A juíza já está em casa e passa bem. Numa palestra dada por essa juíza, ela lembrou que uma mulher é agredida a cada quinze segundos no Brasil, segundo pesquisa feita pela Fundação Perseu Abramo. Pela apuração que eu fiz ela é uma juíza super séria, dedicada, querida pelos colegas. Então doutora, não tenha medo, se recupere, volte a trabalhar, porque a sociedade e todos nós precisamos da senhora. Apresentador, 31/03/16.

Outro tema recorrente nos telejornais que trata do cotidiano da metrópole é a situação precária do transporte público. Na $1^{\mathrm{a}}$ edição do SPTV do dia 19 de abril, o assunto de abertura do telejornal é justamente a situação dos trens lotados, prejudicando a população. $\mathrm{O}$ apresentador César Tralli afirma que:

O que era ruim ficou ainda pior. Ladrões roubaram fios da subestação Calmon Viana, na quinta passada, desde então o intervalo dos trens subiu 50\%. A CPTM não conseguiu resolver o problema ainda. Apresentador, 19/04/16.

Como é tradicional nesta edição do telejornal, o apresentador chama o repórter Filippo Mancuso ao vivo do local do acontecimento jornalístico, reforçando a estratégia de presença do telejornal no momento em que os fatos acontecem. 
O repórter chama a matéria que detalha os problemas na demora dos trens em função do roubo de fios na estação. Ao longo da reportagem, o repórter destaca as fotos enviadas por um telespectador.

Até no fim de semana as pessoas passam sufoco. Como mostram essas fotos mandadas pelo Pedro Luiz, de Suzano. São da estação Guaianazes, no domingo, dia 20 de março. Nesse dia, ele ouviu do alto falante da CPTM que a lentidão era por causa da manutenção. Repórter, 19/04/16.

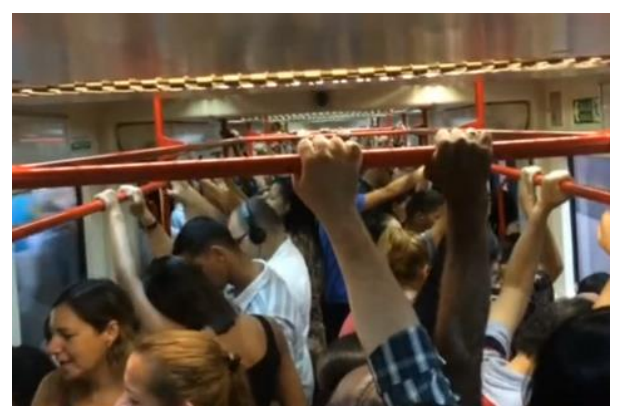

Figura 4: Problema no transporte público. Passageiro registra trem lotado.

O texto narrado pelo repórter reforça a falta de infraestrutura adequada à população que precisa utilizar o transporte público inclusive nos fins de semana. Além da utilização das imagens enviadas pelo telespectador, o repórter utiliza na matéria a informação sobre o possível motivo da lentidão, destacando mostrando que o cidadão que registra essas imagens também se preocupa em contextualizá-las, buscando informações complementares que possam "esclarecer" os fatos.

Tensionamento entre estudantes e policiais militares foram registrados por alunos que haviam invadido uma escola técnica na capital paulista. Eles invadiram as escolas e delegacias de ensino para protestar contra a falta de merenda. A reportagem foi exibida no SPTV $1^{\text {a }}$ edição, do dia 13 de maio.

A repórter Bruna Vieira entra ao vivo no telejornal em frente a uma delegacia para onde foram levados os alunos que haviam invadido uma escola. Durante a reportagem, são exibidas imagens feitas pelos estudantes no momento do conflito: 
Os estudantes fizeram essas imagens na hora da retirada. Repórter, 13/05/16.

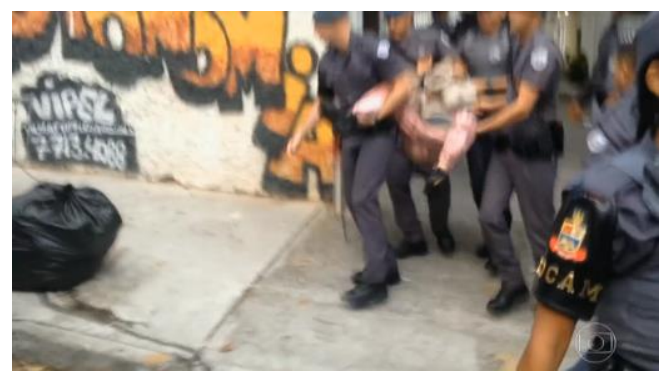

Figura 5: Estudantes registram policiais retirando à força alunos do local invadido.

Após o término da reportagem, Tralli faz uma crítica aos alunos que invadiram as escolas.

Que moral os manifestantes tem de ocupar uma escola e depois deixar nesse estado. Destruir, roubar, vandalizar. Não pode né gente, é patrimônio público. Tem que saber cuidar. Os manifestantes deveriam dar bom exemplo, cuidar, zelar e na hora de ir embora, limpar. Falar ô tá aqui, fizemos o nosso protesto e tá aqui, devolvemos. Era isso que tinha que acontecer. Apresentador, 13/05/16.

No discurso final do apresentador, entendemos que a reportagem dá uma maior ênfase à situação da escola deixada pelos alunos, retirados à força, ao invés de problematizar a legitimidade do protesto dos alunos em função da falta de merenda, que deveria ser oferecida obrigatoriamente pelo Estado. Nesse sentido, a reportagem deixa de focar na ausência do poder público diante dos seus compromissos com a população para tratar da situação da escola deixada pelos alunos.

Novamente a saúde pública é destaque no telejornal a partir de imagens enviadas pelos telespectadores. Na matéria exibida no dia 14 de junho, no SPTV $1^{\mathrm{a}}$ edição, pacientes e funcionários registram a falta de material hospitalar para atender a população.

O apresentador César Tralli afirma que funcionários e pacientes do hospital Vila Penteado, um dos maiores da zona norte de São Paulo, passaram a denunciar falta de materiais básicos, como gases, ataduras, álcool e até mesmo remédios. Na matéria feita pelo repórter Philipe Guedes, são exibidas fotos enviadas por um telespectador, paciente do hospital.

Assim também aconteceu com outro paciente, Eduardo Araújo da Silva ele mandou fotos dele na sala pré-cirúrgica, mas a operação não foi feita. Eduardo mostrou esse documento assinada por uma médica dizendo que o motivo foi a falta de material. Repórter, 14/06/16. 


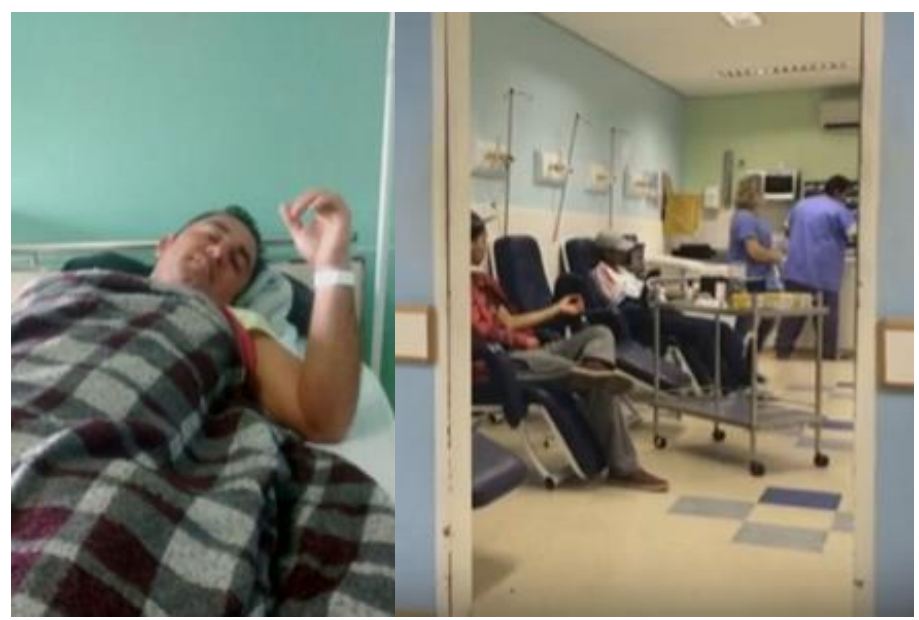

Figura 6: Pacientes e funcionários registram falta de material para atender população no hospital.

Após a reportagem, o apresentador faz duras críticas à saúde pública, reforçando mais uma vez o papel de "defensor" dos cidadãos junto ao poder público atribuído aos jornalistas.

É o retrato da humilhação. A falência da saúde pública. Você tem que pagar do bolso por um medicamento, por um exame que o hospital deveria te dar. É o fim da picada. O diretor do hospital negou que esteja faltando material e que os casos mostrados na reportagem são pontuais. Apresentador, 14/06/16.

O material exibido pelo SPTV 1a edição no primeiro semestre de 2016, de acordo com os exemplos aqui mostrados, é sem dúvida uma estratégia empresarial, em meio à crise no jornalismo que contribui para um enxugamento nas redações dos veículos de comunicação. No entanto, como apontam Musse e Thomé (2015, p.09), “[...] há de se considerar que a possibilidade de veiculação de denúncias e flagrantes feitos por cidadãos que vivem situações as mais adversas na cidade [...] garante uma pluralidade nos registros do cotidiano da pessoa comum, dando maior autenticidade à cobertura jornalística regional”.

Nesta breve avaliação do telejornal SPTV $1^{\mathrm{a}}$ edição, compreendemos que valores identitários sobre a cidade de São Paulo são reforçados por meio do discurso jornalístico. A televisão constrói, portanto, significados, apoiando-se em sistemas menos formalizados. Ela trabalha com uma linguagem propriamente que representa a realidade a partir de critérios funcionais com características técnicas e linguísticas.

A primeira edição do SPTV é marcadamente construída para estar em cima do fato, com a utilização de muitos links ao vivo, reforçando a presença do telejornal em diversas regiões da cidade. As reportagens exibidas reforçam representações sobre os problemas vividos cotidianamente pelos moradores da cidade de São Paulo a partir da apropriação, pela emissora, das imagens produzidas pelo público telespectador. 
Identificamos que as imagens, em vídeo ou foto, utilizadas nas reportagens reforçam o lado negativo da cidade, como precariedades na saúde, educação, segurança e transporte público. Neste sentido, reforça-se a identidade dos jornalistas mediadores e dos cidadãos participantes. A elaboração de notícias com a participação do público, apesar de ainda incipiente, pode contribuir para a pluralidade de perspectivas de enunciação no telejornalismo. É nessa perspectiva que localizamos a contribuição do jornalismo no desenvolvimento da democracia.

\section{REFERÊNCIAS}

CASTELLS, Manuel. A sociedade em rede. São Paulo: Paz e Terra, 1999.

CHARAUDEAU, Patrick. Discurso das mídias. São Paulo: Contexto, 2006.

CORREIA, João Carlos. Teoria e Crítica do Discurso Noticioso - Notas sobre Jornalismo e representações sociais. Covilhã: Universidade da Beira Interior, 2008.

DUARTE, Bastos Elizabeth e CURVELLO, Vanessa. Telejornais: Quem dá o tom? In: GOMES, Itania Maria Mota (org.). Televisão e Realidade. Edufba, 2009.

FINGER, Cristiane. O telejornalismo na hipertelevisão: os desafios dos produtores e dos receptores das notícias no mundo multitelas. In: VIZEU, Alfredo; MELLO, Edna; PORCELLO, Flávio; COUTINHO, Iluska (orgs.) Telejornalismo em Questão. Coleção Jornalismo Audiovisual. V.3. Florianópolis: Insular, 2014.

HALL, Stuart. Da Diáspora: Identidades e Mediações culturais. Belo Horizonte: UFMG; Brasília: Unesco, 2003.

JIMENEZ, Jesús Garcia. Narrativa Audiovisual. Madrid: Cátedra, 1996.

JOST, F. Seis lições sobre televisão. Porto Alegre: Sulina, 2004.

KIELING, Alexandre. Conteúdo colaborativo na TV: formulações para a figura narrativa do telespectador. Artigo apresentado no GT Estudos de Televisão. Juiz de Fora: COMPÓS, 2012.

MOSCOVICI, Serge. Representações sociais: investigações em psicologia social. Rio de Janeiro, Vozes, 2003.

MOTA, Célia. O gesto e a palavra: representações sobre cidadania no telejornal. In: PORCELLO, Flávio; VIZEU, Alfredo (orgs.). Telejornalismo: a nova praça pública. Florianópolis: Insular, 2006.

MOTTA, Luiz Gonzaga. Narratologia: teoria e análise da narrativa jornalística. Brasília: Casa das Musas, 2004. 
MUSSE, Christina Ferraz; THOMÉ, Cláudia de Albuquerque. Um milhão de amigos no RJTV: o telespectador como produtor de conteúdo pelos aplicativos WhatsApp e Viber. Sessões do Imaginário, v.20, n. 33, p. $01-09$, Porto Alegre: 2015.

SCOLARI, Carlos. Hacer Clic. Hacia una sociosemiótica de las interacciones digitales. Barcelona: Gedisa, 2004.

SQUIRRA, Sebastião. Aprender Telejornalismo: Produção e Técnica. São Paulo: Editora Brasiliense, 1995.

TOURINHO, Carlos. O tempo da "hipertelevisão". Observatório da Imprensa. Ed. 684, 06 mar. 2012. Disponível em: http://observatoriodaimprensa.com.br/feitos-desfeitas/ed684-o-tempo-dahipertelevisao/. Acesso em: 12 mar. 2012.

\section{Original recebido em: 10 de janeiro de 2017}

Aceito para publicação em: 21 de junho de 2018

Vicente William da Silva Darde

Jornalista, Mestre e Doutor em Comunicação pela UFRGS. Professor e Coordenador do Mestrado Profissional em Jornalismo do FIAM-FAAM Centro Universitário. Professor e Coordenador dos Cursos de Jornalismo e Relações Públicas do FIAM-FAAM Centro Universitário.

Fernando Albino Leme

Jornalista, Mestre em Comunicação pela UNIP. Doutorando em Comunicação pela UNIP. Professor e Coordenador do Curso de Graduação em Rádio e TV, CST em Produção Audiovisual e CST em Produção Multimídia do FIAM-FAAM Centro Universitário.

\section{(2) $\odot \Theta(\odot)$}

Esta obra está licenciado com uma Licença Creative Commons Atribuição-NãoComercial-CompartilhaIgual 4.0 Internacional 